\title{
DIFFUSION CAPILLAIRE DE L'EAU DANS LE SOL ET PROFILS HYDRIQUES
}

\section{HALLAIRE}

Institut National de la Recherche Agronomique,

Versailles (Seine et Oise), France

La considération des profils hydriques observés en sol nu et cultivé conduit à préciser la loi de variation du potentiel capillaire $\psi$ avec la profondeur $\mathrm{Z}$ : tandis que les profils hydriques (en taux d'humidité) sont parfois irréguliers, notamment ceux observés en sols hétérogènes, par contre le potentiel capillaire $\psi$ décroit régulièrement avec la profondeur (Fig. 1).
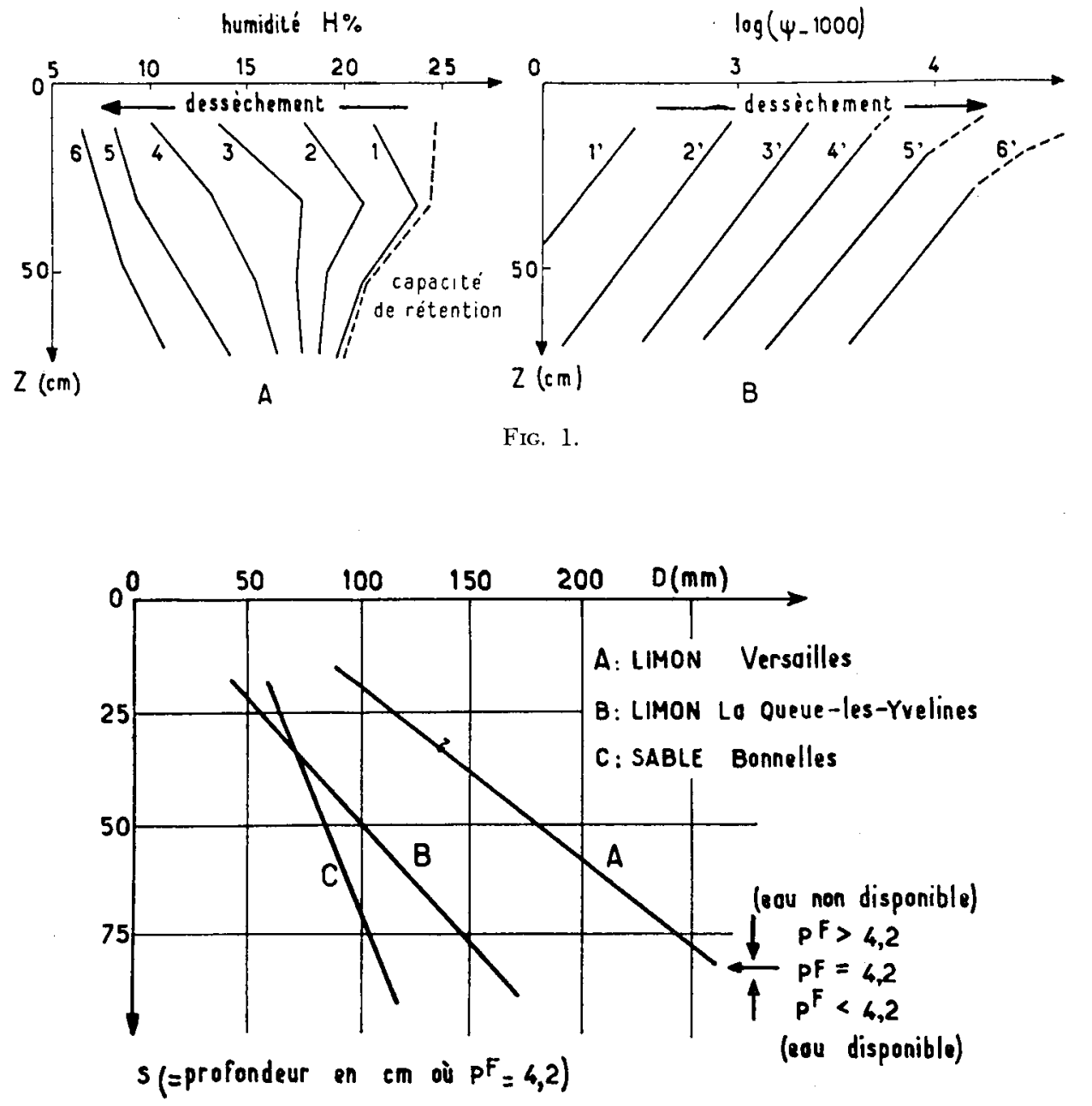

FIc. 2. 
Pour expliquer la variation trouvée de $\psi(Z)$, on est amené à formuler plusieurs hypothèses. On doit admettre en particulier que pour un sol donné le débit per ascensum (sous forme liquide) ne peut dépasser une certaine valeur critique. Cette dernière, d'après des expériences de laboratoire, serait de l'ordre de $1 \mathrm{~mm}$ par jour.

En ce qui concerne le problème de l'évapotranspiration, l'ensemble des résultats sur les profils hydriques et sur les valeurs correspondantes de $\psi$ montre que le déficit critique au-delà duquel l'évapotranspiration réelle est susceptible de devenir systématiquement inférieure à $E_{p}$, variera de 75 à $200 \mathrm{~mm}$ environ suivant la nature du sol (Fig. 2). En outre avant que soit atteint ce déficit critique, l'évapotranspiration réelle pourra être limitée par la valeur maximur. du débit per ascensum. 